\title{
THE ENCAPSULATION OF METFORMIN ON CHITOSAN MATRIX AS DIABETES MELLITUS DRUG SLOW RELEASE SYSTEM
}

\author{
S. E.Cahyaningrum", N. Herdyastuti, W. Imroni and A. Sholikhah \\ Department of Chemistry, Faculty of Mathematics and Natural Science, \\ Universitas Negeri Surabaya, Indonesia-60231 \\ *E-mail: saricahyaningrum@unesa.ac.id
}

\begin{abstract}
This study was aimed to encapsulation metformin, the diabetes melittus type 2 drugs. In this study, chitosan-alginat and tween 80 composites were used as matrix encapsulation. The chitosan was mixed with variation of the composition of metformin- calcium alginate- tween 80 . The effectivity of encapsulation was evaluated from surface morphology, functional group, \% drug encapsulation efficiency and effect soaked on stability encapsulation. The metformin encapsulated was characterized to analysis of the functional group and particle size. The results showed that the metformin encapsulated a slightly rough surface with a good appearance. The drug encapsulation efficiency was about 7.06 to $30.32 \%$.
\end{abstract}

Keywords: Encapsulation, Metformin, Diabetes Mellitus, Chitosan, Slow-release System

( ) RASĀYAN. All rights reserved

\section{INTRODUCTION}

Diabetes Mellitus represent the disease effect of distinguished by trouble body metabolism is blood glucose rate height (hyperglichemia) accompanied by trouble at carbohydrate metabolism, protein and lipid as the impact of reducing insulin function. The operation of blood glucose was represented one of the important pillars for the attainment of operation of blood glucose so that can lessen the risk of complication (macrovascular and microvascular) at type diabetes 1 and also type 2. One of its ways is with consuming metformin that is diabetes regularly. Metformin represents drug of diabetes type 2 that available in the form of tablets, its biological bill time only 1.5 hours so that patient has to consume 2-3 times one day continually. ${ }^{1-4}$ Usage continually can improve the risk of lactate acidosis so that can cause fatally. Some research has been developed, studied and applied for the patient to drug administration. Which has been shown to reduce the side effects, highly efficient, cheaper, and is effective to administer. ${ }^{5,6}$ One of the ways to overcome it is by improving biological bill time that is with encapsulation this drug use composite material..$^{7-9}$ In this study is use the composites alginate chitosan and added with surfactant. The target of this research is to make nanocomposite metformin as a drug for diabetes type 2 slow-release system, so that will be yielded with quality which better than diabetes drug type 2 which have there is during the time. The method of encapsulated metformin in alginate-chitosan composite expected as a method capable to protect the drug from the condition of damaged external environment at the same time send the drug to goals place. ${ }^{10,11}$ The encapsulation of compound in nanocomposite should be used for the minimization of its insufficiency. ${ }^{12-13}$ The encapsulation process of metformin in this research uses a double counting system there are in alginate and chitosan. Silva ${ }^{13}$ usage of a double counting system of alginate-chitosan can lessen porosity and improve stability of yielded capsule. Alginate and chitosan have used many in course of encapsulation because in character which is biocompatible, nontoxic and cheaper. ${ }^{13-15}$ Freedli and Schlager ${ }^{1}$ showed that the process of capsule use alginate takes place at the condition of soft so that do not destroy materials which are its cladding. Its excess enable alginate used in insulin encapsulation and also bacterium live without loss of activity in the biological activity. ${ }^{1,6}$ The use of chitosan for matrix in encapsulation has some studied. The application

Rasayan J. Chem., 13(1), 389-394(2020)

http://dx.doi.org/10.31788/RJC.2020.1315551

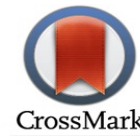




\section{RASĀYAN J. Chem.}

Vol. 13 | No. 1 |389 - 394| January - March | 2020

chitosan has also upon which bioadhesive in the field of pharmacy. Its ability upon which bioadhesive will make a capsule is longer in the intestine wall so that active compound inhibition will mount. Chitosan is a natural biomaterial with potential in medical applications. Chitosan was produced from deacetylation of chitin. ${ }^{16-19}$ Some polymers can be used to the encapsulated drug, for example, glutaraldehyde- chitosan ${ }^{20}$; gelatin. ${ }^{21}$ The combination of chitosan with materials yielding the effect of synergies will be beneficial to be used as hemodialysis membrane ${ }^{22}$ and matrix at microencapsulation medicine. ${ }^{23}$ This research aims to yield a drug of diabetes that encapsulation use double cladding system there is alginate-chitosan composite.

\section{Material and Methods}

\section{EXPERIMENTAL}

Calcium chloride, Sodium alginate, Sodium hydroxide, Acetic acid, chloride buffer solution $\mathrm{pH}$ 1.2, phosphate buffer solution $\mathrm{pH} 7.4$ other chemicals were were used as analytical grade and purchase from Merck Company; Tween 80 (polyethylene sorbitan monooleate) and metformin was purchase from PT Kimia Farma Indonesia. Chitosan with 85\% deacetylated was obtained from Chitosindo Indonesia.

The equipment utilized in this experiment were Spectrophotometer Infra-Red (FTIR Perkin Elmer Frontier-89485), SEM Zeiss, JSM-1600 for morphology analysis, Particle size was analysis with Zetasizer 3000HS and Spectrophotometer UV-Vis Shimadzu-1700 was for metformin analysis

\section{General Procedure \\ Encapsulation Metformin with Alginate}

The alginate solution $2 \%(\mathrm{~b} / \mathrm{v})$ and metformin was mixed with variation composition mass of alginate: metformin, there are $1: 1 ; 1: 1.25 ; 1: 1.5 ; 1: 2$ and $2: 1$. The solution and then was dropped with calcium chloride $0.15 \mathrm{M}$. The encapsulated metformin was washed with aqua dest.

\section{Coating Metformin Encapsulated with Chitosan}

Metformin encapsulated with alginate was soaked in condensation of chitosan. The concentration of chitosan was used to be made were a variation that is $0,1-0,5 \%(\mathrm{~b} / \mathrm{v})$. The time of soaked was variation, which is 10-30 minutes, after filtered and dried at room temperature for 24 hours. Obtained [ by alginatechitosan encapsulation metformin. The metformin encapsulated was characterized: morphology with SEM and mass test.

\section{The Efficiency of Encapsulation}

Counted $50 \mathrm{mg}$ metformin encapsulated was deliberated and dissolved into phosphate buffer $100 \mathrm{ml}$ in $\mathrm{pH}$ 7.2. The mixture was shaken during the last 24 hours. After then, the filtrate was analyzed with spectrophotometer UV-vis $262 \mathrm{~nm}$ to determine the free metformin from the matrix.

\section{The Analysis of Swelling Index}

The swelling index was analyzed with method: metformin encapsulated were immersed in a buffer solution at $\mathrm{pH} 7.4$ and 1.2 in room temperature in various time intervals. After the metformin encapsulated were immersed, the excess water was removed using filter paper, the weight of the swollen metformin was weighed. The procedure was repeated until constant. The swelling index of metformin encapsulated was calculated with the equation:

$$
\% \text { Swelling }=\frac{W a-W b}{W b} \times 100
$$

Where, $\mathrm{Wa}$ and $\mathrm{Wb}$ represent the weight of swollen and dry metformin encapsulated, respectively.

\section{Encapsulation of Metformin on Alginate-Chitosan}

\section{RESULTS AND DISCUSSION}

The process of encapsulation Metformin was done with a double cladding model that is the metformin was encapsulation at alginate after then cladding at chitosan. Chitosan and alginate were ionic bonds one another caused by difference electronegativity. The negative charge negative from alginate, while the 
RASĀYAN J. Chem.

Vol. 13 | No. 1 |389 - 394| January - March | 2020

positive charge from chitosan. Negative charge alginat because of the existence of functional of carboxyl positive charge and chitosan come from the amino functional group.

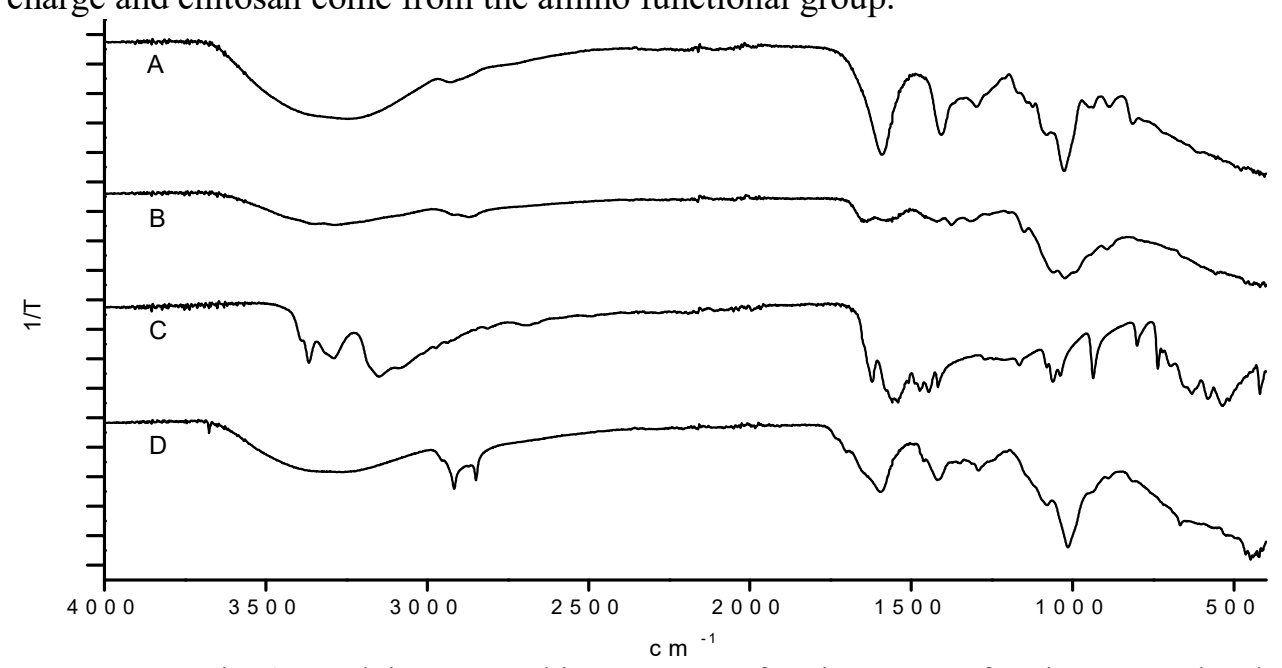

Fig.-1: A-Alginate, B-Chitosan, C-Metformin, D-Metformin encapsulated

Figure-1 showed the spectra of alginate (A), chitosan (B), metformin (C) and metformin encapsulated (D). The alginate has spectra characteristics is the carboxylate groups. This functional group was dissociated become $\mathrm{COO}^{-}$groups which binds of complexed with protonated amino groups of chitosan through electrostatic interaction. The vibration peaks of chitosan were observed such as the characteristic broad peak at $3445 \mathrm{~cm}^{-1}$ indicated to either $\mathrm{O}-\mathrm{H}$ or $-\mathrm{NH}_{2}$ groups. The functional group $\mathrm{NH}_{2}$ has a band is between 1225 and $1035 \mathrm{~cm}^{-1}$. The increase in the intensity spectra at $1653 \mathrm{~cm}^{-1}$ after metformin was encapsulated in calcium alginate chitosan composite (Fig.-1D).

Encapsulation of metformin was early with a cladding of metformin with alginate. The suspension metformin-alginate was dropped into calcium chloride solution cause the happening of crossed binding of alginate molecule with $\mathrm{Ca}^{2+}$ ion. The crossed bonding was caused to be formed gel from alginate for less than 1 minute. The momentary formed gel after the drop has the character to soften. After 10 minutes, gel from alginate becomes harder which anticipated by because crossed tying among alginate and $\mathrm{Ca}^{2+}$ has taken place perfection. After the metformin was encapsulated in alginate, the metformin was done cladded at the chitosan solution. The result of this process can be expected it metformin will spread over into the matrix.

Concentration comparison of metformin: alginate and chitosan used for cladding to have an effect on to total mass of encapsulated metformin yielded. Data in Tables 1 indicating that in general, an increase of concentration of chitosan boost up yielded capsule total mass. The mentioned was anticipated more and more tied chitosan at alginate. However, an increase of concentration of chitosan from 0.3 becoming $0.5 \%(\mathrm{~b} / \mathrm{v})$ degrade matrix mass although do not significant. The mentioned because of osmosis processes from gel to alginate when cladding process in the chitosan solution.

Table-1: Total of Massa Metformin encapsulated on Some Composisition of Chitosan:Alginate:Metformin

\begin{tabular}{|c|c|c|c|c|c|c|}
\hline \multirow{2}{*}{$\begin{array}{l}\text { Composition } \\
\text { Alginat: } \\
\text { Metformin }\end{array}$} & \multicolumn{6}{|c|}{ [Chitosan] \% (b/v) } \\
\hline & 0.1 & 0.2 & 0.3 & 0.4 & 0.5 & 0.6 \\
\hline $1: 1$ & 0.021 & 0.021 & 0.028 & 0.024 & 0.024 & 0.022 \\
\hline $1: 1.25$ & 0.022 & 0.024 & 0.032 & 0.031 & 0.028 & 0.029 \\
\hline $1: 1.5$ & 0.023 & 0.026 & 0.036 & 0.036 & 0.031 & 0.031 \\
\hline $1: 2$ & 0.024 & 0.028 & 0.037 & 0.037 & 0.032 & 0.031 \\
\hline $2: 1$ & 0.021 & 0.023 & 0.024 & 0.025 & 0.023 & 0.022 \\
\hline
\end{tabular}

Silva $^{13}$ please express that gel of alginate has the character of semipermeable. As a result, some metformin goes to the wall exit with water when the cladding phase of chitosan high concentration. Besides the concentration of chitosan, the comparison of alginate-metformin massa also has an effect on 
RASĀYAN J. Chem.

Vol. 13 | No. 1 |389 - 394| January - March | 2020

to obtained metformin encapsulated total mass. The comparison 1:1.5 yielding metformin encapsulated with the highest total mass, while at the comparison 1:2 amount of downhill total mass because the amount of metformin too much so that condensation becomes very jell and difficultly for the encapsulated process. At comparison 2:1 smaller total mass also because of the amount of excessive alginate, condensation very watery the amount of metformin a little bit so that its smaller total mass also compared to comparison 1;1.5 The analysis morphologies showed that surfactant has effect in encapsulated metformin process. The encapsulation process with the addition of surfactant $3 \%$ having a surface is more porous as compared to which do not was add surfactant. Existence of pore will assist easier metformin exit of the matrix so that more effective in running its function as a drug of diabetes mellitus because could suppresses glucose production and reducing LDL cholesterol. ${ }^{24}$
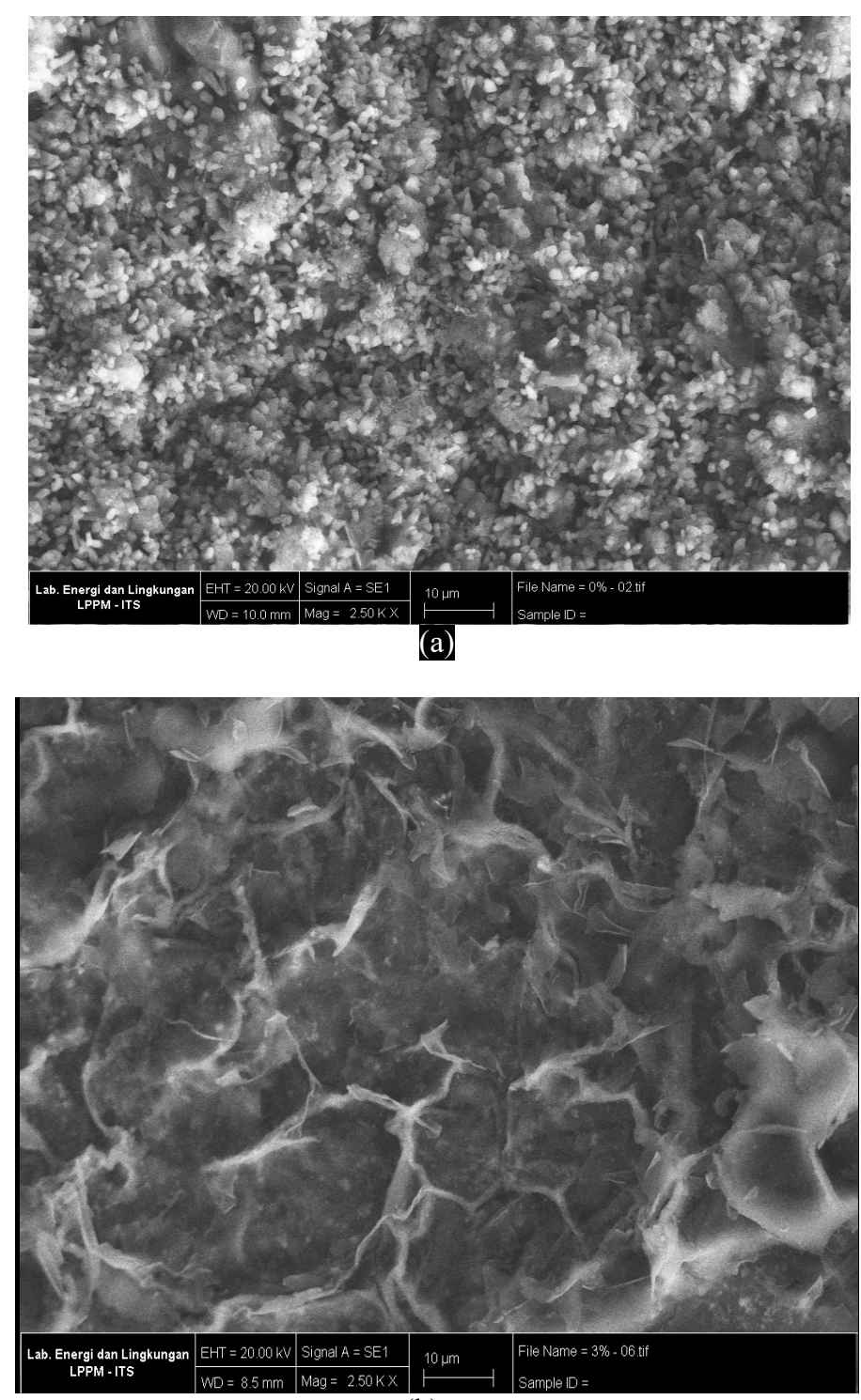

(b)

Fig.-2: Encapsulated of Metformin on Chitosan-Alginate with Tween $80: 0 \%$ (a) and 3\% (b)

The time of soaked llama at chitosan solution chitosan has influence at the mass of metformin encapsulation yielded. The optimum time reached at soaked during 10 minutes, the addition of time of soaked cause degradation of the total mass of metformin encapsulated because some of the natural metformin of osmosis so that go out to chitosan solution. 
RASĀYAN J. Chem.

Vol. 13 | No. 1 |389 - 394| January - March | 2020

Table -2: The Influence of Soaking Time to Massa of Metformin encapsulated

\begin{tabular}{c|c|c|c|c}
\hline $\begin{array}{l}\text { Composition of } \\
\text { Alginate: }\end{array}$ & \multicolumn{4}{|c}{$\begin{array}{c}\text { Massa of Metformin encapsulated } \\
\text { Some Variation of Soaking Time (Minute) }\end{array}$} \\
\cline { 2 - 5 } Metformin & 10 & 10 & 20 & 30 \\
\hline $1: 1.5$ & 0.030 & 0.037 & 0.035 & 0.30 \\
\hline $1: 2$ & 0.032 & 0.038 & 0.036 & 0.030 \\
\hline
\end{tabular}

One of the parameters that are used to determine the efficacy of the encapsulated process is the efficiency of microsperis metformin encapsulation. The efficiency shows how many $\%$ metformin that is the success was encapsulated in matrix.

The increase in the amount of metformin in chitosan will improve the efficiency of is the amount of metformin which is encapsulated. The increase of chitosan concentration was expected will improve thickly of the coat of chitosan. The coat of chitosan will turn into gel at the physiological solution of the functioning and digestive system as a barrier to control the release of the metformin. Thick progressively gel coat of chitosan hence is ever greater of the barrier which must pass by metformin, this matter happened until chitosan solution is $0.3 \%$, at happened higher level concentration of degradation of efficiency because concentration chitosan high cause osmosis of metformin when soaked at chitosan.

Table-3: The Efficiency of Encapsulated Process of Metformin in Some Comparison of Composition

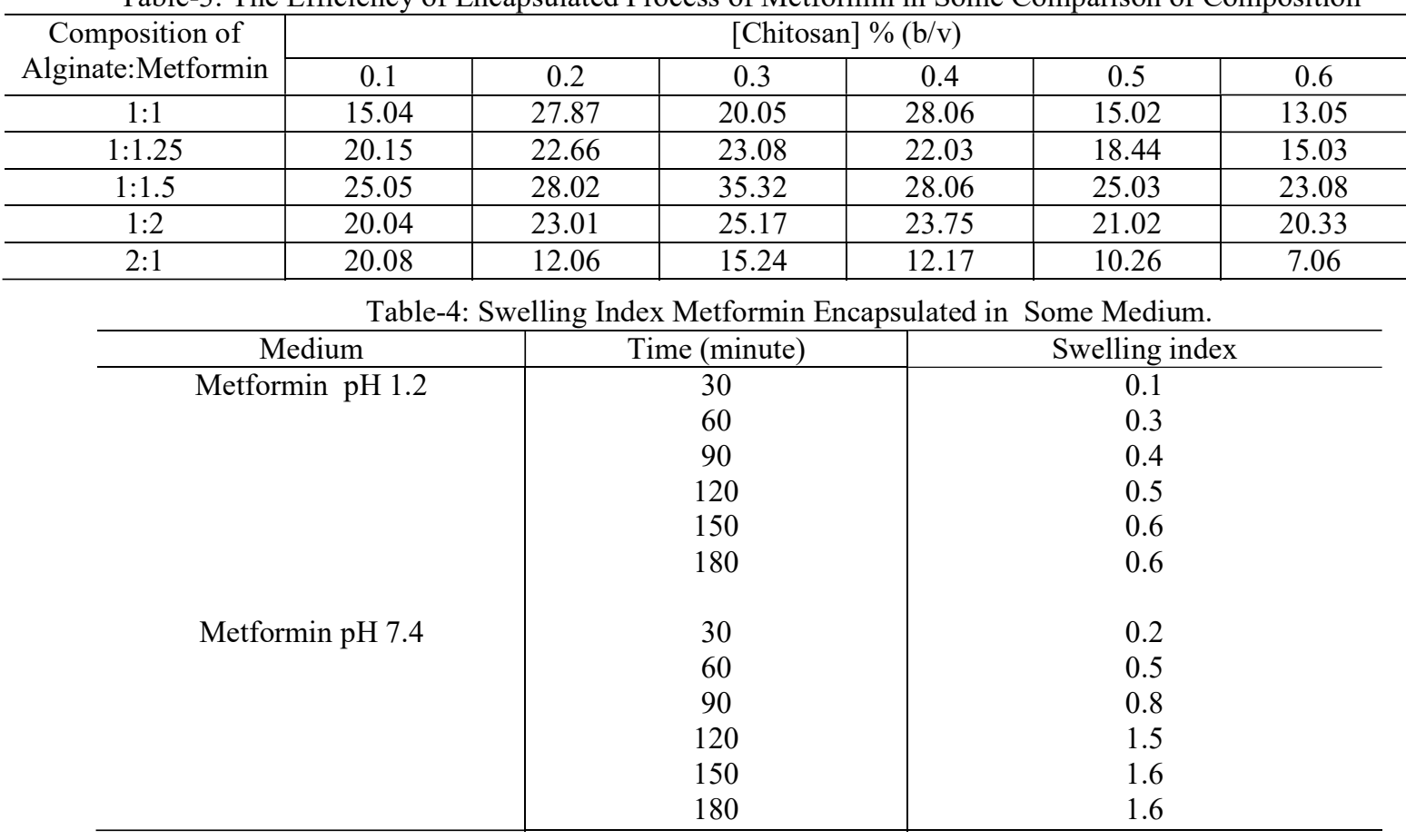

Data test swelling used to know how the index of swelling metformin in various $\mathrm{pH}$ solutions. At this research is used buffer $\mathrm{pH} 1.2$ and $\mathrm{pH} 7.4$ similar to solution in the digestive system. Data at tables 4 indicating that at $\mathrm{pH} 1.2$ the ability of low swelling, because at acid $\mathrm{pH}$ the chitosan representing external coat dissolve and get out of metformin index swelling yielded from alginate swelling. At $\mathrm{pH} 7,4$ the swelling index is high, the mentioned because of chitosan insoluble in high $\mathrm{pH}$ so that can be big puffy. This results given expectation at metformin encapsulated in control at a digestive system which has acid $\mathrm{pH}$.

\section{CONCLUSION}

The encapsulation of metformin used alginate and chitosan was the influence of the comparation of composition alginate: metformin, chitosan concentration and time of soaked. The total massa of metformin encapsulated highest at time soaked is 20 minutes, with composition alginate: metformin is 


\section{RASĀYAN J. Chem.}

Vol. 13 | No. 1 |389 - 394| January - March | 2020

1:1.5 with chitosan concentration is $0.3 \%(\mathrm{~b} / \mathrm{v})$. Encapsulated Metformin with added surfactant produce metformin encapsulated more porous than do not add surfactant. The analysis of the swelling index showed that chitosan dan alginate can effective as a matrix for metformin encapsulation.

\section{ACKNOWLEDGMENT}

The authors thank DRPM for the support of funding in this research with Penelitian Dasar Unggulan Perguruan Tinggi Program 2019.

\section{REFERENCES}

1. A.C Friedli, I.R. Schlager and S.W. Wright, Journal of Chemical Education, 82, 1017(2005), DOI:10.1021/ed082p1017

2. V K. Kamboj, P Kumar Verma, Asian Journal of Pharmaceutical and Clinical Research, 11(8), 212(2018), DOI:10.22159/ajpcr.2018.v11i8.26444

3. V.K. Sharma and A.Bhattacharya, Indian Journal of Pharmaceutical Education and Research, 42(4), 363(2008)

4. C.Qin, W. He, C. Zhu, M. Wu, Z. Jin, Q. Zhang, G. Wang and L.Yin, International Journal of Pharmaceutis, 466 (1-2), 276( 2014), DOI:10.1016/j.ijpharm.2014.03.002

5. M.C Chen, F.L Mi, Z.X Liao, C.W Hsiao, K. Sonaje, M.F Chung, L.W Hsu, H.W Sung, Advance Drug Delivery Reviews, 65, 865(2013), DOI:10.1016/j.addr.2012.10.010

6. R. Ghaffarian, E.P Herrero, H. Oh, S.R Raghavan, S. Muro, Advance Functional Materials, 26, 3382(2016), DOI:10.1002/adfm.201600084

7. S.E. Cahyaningrum, N Herdyastuti, and N Qomariah, Indonesia Journal of Chemistry, 15(1), 16(2015), DOI:10.22146/ijc.21218

8. B. Sarmento, D. Ferreira, F. Veiga, and A. Ribeiro, Carbohydrate Polymers, 66, 1(2006).

9. D Pal and A. K Nayak Drug Delivery, 19(3), 123(2012), DOI:10.3109/10717544.2012.657717

10. S. Babaie, S. Ghanbarzadeh, S. Davaran, M. Kouhsoltani, and H. Hamishehkar, Advance Pharmceutical Bulletin, 5(4), 549(2015), DOI:10.15171/apb.2015.074

11. P. Parhi, C. Mohanty, and S.K. Sahoo, Drug Discovery Today, 17, 1044(2012).

12. A. Chandel, V. Patil, R.Goyal, H. Dhamija, and B. Parashar, Journal of Pharmaceutical Chemistry \& Chemical Science, 1(2), 563(2012).

13. C.M, Silva, A.J, Riberio, M. Figueiredo, D. Ferreira, F. Veiga, AAPS Journal, 7, E903(2006)

14. K.P.R. Chowdary, P. Mohapatra and M.N. Murali Krishna, Rasāyan Journal of Chemistry, 1(1), 99(2008)

15. P.Sabitha, J. V. Ratna and K. R. Reddy, International Journal of ChemTech Research, 2, 88(2010)

16. J. Sheng, L. Han, J. Qin, G. Ru, R. Li, L. Wu, D. Cui, P. Yang, and Y. He, ACS Applied Materials Interfaces, 7(28), 15430(2015), DOI:10.1021/acsami.5b03555

17. S. Senel, S.J McClure, Advance Drug Delivery Reviews,56, 1467(2004)

18. M. Motiei, S. Kashanian, L.A Lucia, and M. Khazaei, Journal of Controlled Release, 260, 213(2017), DOI:10.1016/j.jconrel.2017.06.010

19. Z. Wang, J. Sun, Y. Qiu, W. Li, X. Guo, Q.Li, H. Zhang, J. Zhou, Y. Du, and H. Yuan, Biomaterials, 68, 32(2015), DOI:10.1016/j.biomaterials.2015.07.058

20. Y. Malam, M. Loizidou and A.M Seifalian . Trends in Pharmacological Sciences. 30(11), 592 (2009), DOI: 10.1016/j.tips.2009.08.004

21. P Sugita, and S.I Lestari, Jurnal Nature, 9(1), 32(2006)

22. SE Cahyaningrum, N Herdyastuty, A Firdausi and D Yanrita, Rasayan Journal of Chemistry, 10(3), 959(2017) DOI: 10.7324/RJC.2017.1031635

23. J. Li, C. Cai, J. Li, J. Li, J. Li, T. Sun, L. Wang, H.Wu 1 and G. Yu, Molecules, 23(10): 2661(2018), DOI: $10.3390 /$ molecules23102661

24. C. Varaprasad, Md. Asif and K. Ramakrishna, Rasayan Journal of Chemistry, 8(4), 426 (2015)

[RJC-5551/2019] 